\title{
Percepção socioambiental e pertencimento ao lugar em uma escola pública ${ }^{1}$
}

\author{
HARTMANN, Antonio José2 \\ MOTA, Junior Cesar ${ }^{3}$
}

\section{RESUMO}

Abordar a Educação Ambiental (EA) pelo olhar da fenomenologia é fazer aflorar percepções socioambientais e sensações delas advindas, na busca de potencializar a essência da existência. Este artigo resultou da execução de um Projeto de Ação em EA, desenvolvido com alunos do nono ano, em uma Escola de Ensino Fundamental do município de Gravataí, RS, que teve como objetivo geral, explorar as percepções socioambientais e verificar como o sentido de pertencimento dos alunos está potencializado, em relação ao lugar onde residem e a escola está integrada. Este possível fortalecimento do despertar para o lugar e do pertencimento, partiu de intervenções coletivas junto aos alunos, donde se verificou que os participantes possuem conhecimentos socioambientais e suas percepções acerca do lugar em que vivem estão desenvolvidas, bem como os sentidos sobre serem pertencentes e que a eles pertence o lugar, porém há um modo dispersivo de ser não crítico ou engajado em um agir transformador.

Educação Ambiental. Percepção Socioambiental. Pertencimento ao lugar.

\section{Socio-environmental perception and the belonging to a place in a public school}

\section{ABSTRACT}

Approaching environmental education through the perspective of phenomenology is to bring out socio-environmental perceptions and sensations, in the pursuit of enhancing the essence of existence. This article resulted from the execution of an Action Research Project, developed with ninth grade students in an Elementary School in the city of Gravataí, RS, Brazil, with the general objective of exploring socio-environmental perceptions and verifying how the sense of belonging of the students is enhanced, in relation to the place where

\footnotetext{
${ }^{1}$ Este artigo é resultante dos estudos e da execução de Projeto de Ação em Educação Ambiental desenvolvido no âmbito do Curso de Pós-Graduação em Educação Ambiental, Lato Sensu, da FURG, pela UAB, no Polo de Santo Antônio da Patrulha.

${ }^{2}$ Mestre em educação ambiental, gestão pública municipal e Docência no Ensino Superior Bacharel em Administração pela ULBRA. Técnico em Segurança no Trabalho pelo SENAC/FUNDACENTRO. E-mail: hartmann.aj@gmail.com. Lattes: http://lattes.cnpq.br/3195478107790212. ORCID: https://orcid.org/0000-0002-1921-9884.

${ }^{3}$ Doutor em educação ambiental. E-mail: juniormota@furg.br. Lattes: http://lattes.cnpq.br/3073364058232279. ORCID: http://orcid.org/0000-0003-0340-8856.
}

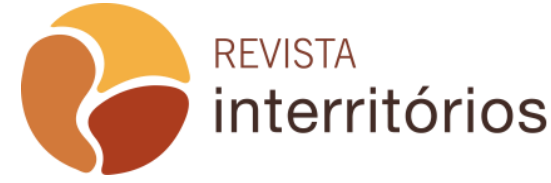

Interritórios | Revista de Educação Universidade Federal de Pernambuco, Caruaru, BRASIL | V.6 N.10 [2020] 
they live the school is integrated. This possible strengthening of the awareness and belonging came from collective interventions with the students, from which it was found that the participants have socio-environmental knowledge and their perceptions about the place where they live are developed, as the meanings about belonging and, also, that the place belongs to them but the participants seem to be disconnected, not critical neither engaged in transformative action.

\section{Environmental Education. Social-environmental perception. Belonging to the place.}

\section{Percepción socioambiental y pertenencia a un lugar en una escuela pública}

\section{RESUMEN}

Acercarse a la Educación Ambiental (EA) a través de la mirada de la fenomenología es poner de manifiesto las percepciones y las sensaciones socioambientales que surgen de ellas, en la búsqueda de mejorar la esencia de la existencia. Este artículo resultó de la ejecución de un Proyecto de Acción en $E E$, desarrollado con estudiantes de noveno grado, en una escuela primaria en la ciudad de Gravataí, RS, que tenía como objetivo general, explorar las percepciones socioambientales y verificar cómo el sentido de pertenencia de estudiantes se mejora, en relación con el lugar donde viven y la escuela está integrada. Este posible fortalecimiento del despertar al lugar y la pertenencia, comenzó a partir de intervenciones colectivas con los estudiantes, a partir de las cuales se descubrió que los participantes tienen conocimiento socioambiental y sus percepciones sobre el lugar donde viven, así como los significados sobre pertenencia y que el lugar les pertenece, pero existe una forma dispersa de no ser crítico o involucrarse en una acción transformadora.

Educación ambiental. Percepción socioambiental. Perteneciente al lugar.

\section{Percezione socio-ambientale e appartenenza a un posto in una scuola pubblica}

\section{SINTESE}

Avvicinare l'Educazione Ambientale (EA) attraverso lo sguardo della fenomenologia è far emergere percezioni e sensazioni socio-ambientali che ne derivano, nella ricerca di migliorare l'essenza dell'esistenza. Questo articolo è nato dall'esecuzione di un progetto di azione in EE, sviluppato con gli studenti della nona elementare, in una scuola elementare nella città di Gravataí, RS, che aveva come obiettivo generale, esplorare le percezioni socio-ambientali e verificare come il senso di appartenenza degli studenti è migliorato, in relazione al luogo in cui vivono e alla scuola è integrata. Questo possibile rafforzamento 
del risveglio verso il luogo e l'appartenenza, è iniziato da interventi collettivi con gli studenti, dai quali è emerso che i partecipanti hanno conoscenze socioambientali e le loro percezioni sul luogo in cui vivono, nonché i significati sull'appartenenza e che il posto appartiene a loro, ma esiste un modo dispersivo di essere non critici o impegnati in azioni trasformative.

Educazione ambientale. Percezione socio-ambientale. Appartenente al posto.

\section{CONSIDERAÇÕES INICIAIS}

A necessidade de compreender os fenômenos na sua totalidade e complexidade vem sendo cada vez mais urgente na contemporaneidade. Para isto, considerar a existência de conhecimentos já construídos, a bagagem sociocultural trazida por cada indivíduo da educação formal escolar, da não formal, da vivência individual, da sua construção pessoal e do convívio social, se torna inexorável nesse processo de compreensão. Assim, é preciso ponderar que cada um dos seres humanos está integrado, faz parte, interage com o meio ambiente, com seus componentes bióticos e abióticos e o percebe enquanto experiência suas vivências. Isto, pois, "o mundo que nos é revelado por nossos sentidos e pela experiência de vida, parece-nos à primeira vista o que melhor conhecemos, [...] basta-nos abrir os olhos e nos deixarmos viver para nele penetrar" (MERLEAU-PONTY, 2004, p. 1).

Assim sendo, ao considerar que a percepção nos revela o mundo por meio dos nossos sentidos, experiências e saberes, este artigo é oriundo de um Projeto de Ação em Educação Ambiental (EA) realizado com alunos do nono ano de uma Escola Municipal de Ensino Fundamental (EMEF) da cidade de Gravataí (RS), e ancora-se no objetivo de explorar as percepções socioambientais e verificar como o sentido de pertencimento destes alunos está potencializado, em relação ao lugar em que residem e onde a escola está integrada.

Tendo como alicerce o objetivo apresentado, emergiu a seguinte questão norteadora: Como são manifestados o sentido de pertencimento ao lugar e as percepções socioambientais por alunos do ano final de uma escola municipal de ensino fundamental? Sendo justificativa para este projeto, o tema e seu enfoque, pautada pelo campo de estudos do curso, a EA, bem como pelo interesse do pesquisador em envolver pessoas e questões ambientais em relação à região onde reside, buscando averiguar as percepções socioambientais e o sentido de pertencimento ao lugar em que vivem, o socioambiente ${ }^{4}$ comum.

\footnotetext{
${ }^{4} \mathrm{O}$ termo "socioambiente" é encontrado em publicações do Ministério do Meio Ambiente e em outras, não governamentais, não sendo usual e difundido como o termo 'socioambiental', o qual se refere aos componentes do socioambiente. Sendo então, o espaço geográfico, o lugar,

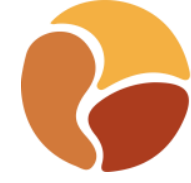

REVISTA

interritórios

Interritórios | Revista de Educação Universidade Federal de Pernambuco, Caruaru, BRASIL | V.6 N.10 [2020]
} 
Seja pelos diferentes conceitos que são apresentados, nos seus fundamentos e mesmo nas mais variadas práticas e modelos que se atribuem à EA, se pode observar que ela não é uma só, singular, mas plural, assim como o meio ambiente não é um só, sendo na realidade vários "meio ambientes", distintos, conectados, interligados, interdependentes e em constante interação. Assim, ao se desenvolver ações em EA, estas também apresentam identificação com diferentes concepções, correntes, se adequando aos vários fatores e variáveis, relacionados com as suas propostas, o meio e os recursos de que se dispõe, por exemplo.

A identificação das proposições, da concepção de meio ambiente e de práticas em EA podem ser enquadradas em modelos pré-definidos, como nas diferentes correntes de EA, conforme Sauvé (2005), não sendo, no entanto, estes enquadramentos rígidos e impermeáveis. Isto porque a práxis muitas vezes pode encontrar rotas de fuga ao se deparar com diferentes realidades, buscando nas mais diversas correntes teóricas da EA subsídios que permitam a compreensão de um fenômeno a ser explorado. Logo, há convergência entre as correntes, não sendo algo estático, enquadrado e moldado em apenas uma ou outra concepção.

Com relação ao seu enquadramento, buscou-se uma atribuição identitária para este artigo, o qual se alinha com as concepções da corrente holística, considerando características, conceitos, concepções, traços marcantes e práticas das correntes, humanista, da crítica social e da ecoeducação, simultaneamente.

Com relação à corrente holística, segundo o Dicionário Priberam da língua portuguesa, é a concepção, nas ciências humanas e sociais, que defende a importância da compreensão integral dos fenômenos e não a análise isolada de seus constituintes e, segundo Sauvé (2005, p. 27), "não associa proposições necessariamente homogêneas". Ainda, para a autora, este olhar holístico se refere à totalidade de cada ser, de cada realidade experienciada, e às múltiplas relações que unem os seres entre si em múltiplos conjuntos onde eles adquirem sentido e razões para permanecerem unidos (SAUVÉ, 2005).

o território, considerando nestes as interações dos grupos humanos (sociedades) com o ambiente, a interação do social com o ambiental, seja este natural ou antropogênico. Seu conceito, pelo apurado, vem da Geografia, dos campos de estudos das relações, das interações do homem com o ambiente e entre os grupos humanos. Conforme Tassara e Ardans (2007), "Os geógrafos Aziz Ab'Saber e Milton Santos, parafraseando o que o conhecimento desenvolvido pela Geografia ao longo dos séculos XIX e XX consolidou sobre o conceito de ambiente geográfico, o definem como socioambiente, ou seja, "a organização humana no espaço total, que compreende os fragmentos territoriais em sua totalidade". (AB'SABER, 2002)". 
Da corrente humanista, por sua vez, emerge um enfoque cognitivo, indo além dos elementos biofísicos do meio, considerando fatores sociais e do próprio ser, a cultura, a história, política, estética, o meio ambiente além do natural. Esses fatores não podem ser abordados sem considerar seus significados, valores simbólicos, bem como suas singularidades e complexidades (SAUVÉ, 2005).

Em relação aos traços da corrente da crítica social, que tem por base o questionamento das relações e, dentre estas as de poder, há uma insistência "essencialmente, na análise das dinâmicas sociais que se encontram na base das realidades e problemáticas ambientais" (SAUVÉ, 2005, p. 30). Logo, esta corrente permite que os fenômenos de uma realidade possam ser compreendidos a partir das relações de vida que se estabelecem em determinado lugar, buscando possíveis alternativas para a solução ou a mitigação dos problemas socioambientais.

Em relação à ecoeducação, esta aborda a EA na perspectiva do desenvolvimento do ser em si, não de resolução de problemas ambientais, mas de fundamentar o agir pessoal responsável. Para Sauvé (2005, p. 35), esta corrente "está dominada pela perspectiva educacional da educação ambiental.". Ainda, para a autora, ela não visa à resolução pontual de problemas, mas valorizar as relações estabelecidas com o meio ambiente para o próprio desenvolvimento pessoal, resultando em ações significativas e responsáveis em prol da qualidade de vida socioambiental (SAUVÉ, 2005).

Posto isto, é possível verificar nos estudos das correntes de EA que os modelos se sobrepõem. Suas teorias, objetivos e métodos de ação muitas vezes se confundem. Assim, em cada etapa executada do Projeto de Ação em EA, possivelmente se migrou entre as correntes ou se esteve em território de diferentes correntes simultaneamente. No entanto, houve o cuidado de manter uma linha que caracteriza uma EA crítica e transformadora, que instigasse os participantes à reflexão, não caindo em práxis ambientais reducionistas ou no simplismo conservacionista de cunho meramente recursista, utilitarista ou mesmo naturalista.

Interligado à concepção holística e às correntes apresentadas, buscamos trazer os pressupostos epistemológicos da fenomenologia, que valoriza a perspectiva qualitativa, as experiências dos pesquisados, sua singularidade e, seus diferentes saberes, que por sua vez, dialogam entre si e com o ambiente. Tal enfoque permite compreender concepções sobre questões socioambientais, bem como as experiências vividas pelos sujeitos que habitam e interagem em um mesmo lugar, neste caso no universo escolar e em seu entorno.

Ressalta-se que para uma melhor organização e compreensão, este artigo está subdividido em seções. Nas Considerações iniciais, são 
apresentadas a temática do trabalho, bem como a justificativa, relevância, a questão norteadora e o objetivo, as concepções e correntes de EA em que este estudo se baseia, bem como a vertente epistemológica. Na sequência, apresenta-se a seção intitulada "A Fenomenologia e a Educação Ambiental: potencializando as percepções e o sentido de pertencimento ao lugar", na qual se debate acerca da fenomenologia, conceitos, método e relações com a percepção do espaço vivido, a educação crítica, emancipatória e transformadora, os ambientes educacionais, a escola como lugar de aprendizado, de relacionamento e transformação social, a relação dialógica entre a Educação e Ambiente, a EA, o socioambiente, o lugar como o espaço das experiências, a percepção e o pertencimento. Posteriormente, se apresenta "Entre o lugar e os sujeitos: onde e com quem as ações se desvelaram", onde é caracterizado o lugar das ações, bem como são apresentados o processo de seleção e características dos participantes. A seguir, na seção "O trilhar da caminhada: interpretando os fenômenos emergentes", são apresentados os dados que emergiram nas etapas de execução, suas compreensões, interpretações e considerações relevantes sobre todo o processo vivido durante a execução junto aos participantes neste projeto. Por fim, as considerações que orientam ao horizonte.

\section{A fenomenologia e a educação ambiental: potencializando as percepções e o sentido de pertencimento ao lugar}

As pesquisas desenvolvidas nos campos da EA, assim como em outros campos do conhecimento, podem ser tratadas de diversas formas e por diferentes métodos, os mais usuais, como os modelos clássicos, nos quais os pesquisadores tratam o objetivismo da pesquisa, utilizam objetivos claros, bem definidos e rígidos, modelos de estudos de casos ou experimentos que precisam de comprovação de verdades, por exemplo. No caso da pesquisa que gerou os dados para compor este artigo, optou-se pela aplicação do enfoque fenomenológico, não tão comum quanto os demais enfoques clássicos utilizados em pesquisas acadêmicas, principalmente fora das áreas da filosofia ou psicologia.

A fenomenologia pensada por Husserl (1986) é uma volta ao mundo vivido, ao mundo da experiência, o ponto de partida de todas as ciências. A Fenomenologia propõe descrever 0 fenômeno, [...], volta-se para as coisas mesmas como elas se manifestam. Voltar às coisas mesmas significa voltar ao mundo da experiência considerando que, antes da realidade objetiva, há um sujeito que a vivencia; antes da objetividade há um mundo 
pré-dado, e, antes de todo conhecimento, há uma vida que o fundamentou. (SADALA, 1995, p. 2).

Com o enfoque fenomenológico, portanto, buscou-se valorizar as experiências dos participantes, suas singularidades conforme seus diferentes saberes que por sua vez dialogam entre si e com o ambiente, buscando compreender as concepções de questões socioambientais, das experiências vividas por diferentes sujeitos que habitam e interagem em um mesmo território, um mesmo socioambiente, neste caso o da escola e em seu entorno. Sendo que,

A pesquisa fenomenológica parte do cotidiano, da compreensão do modo de viver das pessoas, e não de definições e conceitos, como ocorre nas pesquisas desenvolvidas segundo a abordagem positivista. Assim, a pesquisa desenvolvida sob o enfoque fenomenológico procura resgatar os significados atribuídos pelos sujeitos ao objeto que está sendo estudado (GIL, 2008, p. 15).

O interesse pela linha da epistemologia fenomenológica surgiu pela preocupação em investigar a essência dos fenômenos, associar a ciência ao mundo vivido, na aplicação de um método que vai ao encontro das coisas, rejeitando ideias pré-concebidas e que partem do eu e das coisas, indo ao meio ambiente sem considerar fatores inerentes aos seres humanos, suas subjetividades.

Pelo exposto em Gil (2008) e em Sadala (1995), a fenomenologia é qualitativa, no entanto, considerou-se necessário apresentar alguns dados na forma quantitativa, em relação às respostas obtidas, aos sujeitos, os lugares e outros, dando a dimensão destes ao leitor.

Tendo como pilar central o objeto do próprio Curso de Especialização, a EA, buscando um viés crítico, emancipatório e transformador, na relação dialógica Educação e Ambiente, ponderou-se trazer no Projeto de Ação em EA uma proposta de reflexão, integração, de interação e de possível intervenção no cotidiano de pessoas e de seu lugar.

Neste contexto cabe ressaltar que, de acordo com Guimarães (2005, p. 194),

Uma intervenção educacional crítica e emancipatória assume sua dimensão política. É uma EA comprometida com a transformação da realidade rumo a sustentabilidade socioambiental e percebe 0 ambiente educativo como movimento, mas um movimento aderido ao da realidade 
socioambiental, onde se contextualiza. Essa adesão é que possibilita à intervenção educacional transformar a realidade socioambiental e isso se dá por uma práxis educativa (reflexãoação) que potencializa a ação cidadã de sujeitos individuais e coletivos que resistem ao caminho único imposto pela racionalidade dominante.

Desse modo, os ambientes educativos, portanto, só pela transmissão do conhecimento da educação formal e por serem espaços de convivência de diferenças, de encontro da pluralidade, já trazem a significação de formação de seres capazes de entender e avaliar os contextos socioambientais, tomar posição e agirem de alguma forma na sociedade, no socioambiente. Além do conhecimento limitado ao currículo, estes ambientes agregam, ou deveriam agregar saberes extraclasse e ações que levam ao desenvolvimento de indivíduos e de coletivos conscientes de seus papéis e responsabilidades, engajados com as questões socioambientais e sua transformação, tanto no plano global, mas, mais ainda, voltados ao que diz respeito ao seu lugar, seu ambiente próximo, palpável, tangível, onde possam realmente fazer a diferença, o lugar ou lugares nos quais façam parte e sejam os caminhos percorridos em seus cotidianos.

Indo além,

[...] o lugar é carregado de experiências e desejos pessoais, é uma realidade que deve ser compreendida da perspectiva dos que lhe dão significado. Logo, podemos considerar o lugar um conjunto de significados que foram construídos pela experiência. Ele é mais do que uma simples localização. Está carregado de signos e símbolos que resultam de um conjunto de sensações que foram moldadas pelas circunstâncias históricas, econômicas, políticas, sociais e culturais que os indivíduos experienciam, e que apresenta um potencial de afetividade (COUSIN, 2010, p. 91).

Em relação a este ou a estes lugares, emerge o sentimento de pertencimento. Pertencer, neste contexto, em relação ao lugar, traz um sentido de via de mão dupla, o duplo sentido do pertencer a algum lugar e de senti-lo como sendo seu. O sentido de pertencimento em ambos os casos, depende e ocorre, pois, conforme Brandão (2005, p. 16), "atribuímos aos lugares de onde somos e onde vivemos diferentes sentimentos, saberes e significados, de acordo com a maneira como os vivenciamos com os nossos sentidos, a nossa mente e as nossas sensibilidades". Conforme colocado em Guimarães (2005, p. 197), "O espaço em questão pode ser a escola, seu entorno, uma rua, uma praça, uma comunidade, enfim, o objeto de estudo terá a sua dimensão relacionada ao interesse do grupo envolvido".

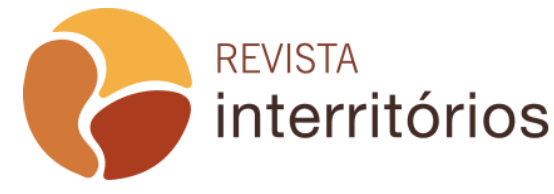

Interritórios | Revista de Educação Universidade Federal de Pernambuco, Caruaru, BRASIL | V.6 N.10 [2020] 
Saindo do ser humano e de suas relações com o meio ambiente, seus sentidos e questionamentos sobre pertencer a algum lugar e de algum lugar lhe pertencer, também a EA, como campo de conhecimento, no mundo da Educação, no ambiente escolar, necessita de tal reflexão e indagação,

[...] afinal, como ocupar um lugar na estrutura escolar desde essa espécie de não-lugar que é a transversalidade? Para a EA, constituir-se como temática transversal pode tanto ganhar 0 significado de estar em todo lugar quanto, ao mesmo tempo, não pertencer a nenhum dos lugares já estabelecidos na estrutura curricular que organiza o ensino (CARVALHO, 2005, p. 61).

A EA é multidisciplinar, tema transverso, ocupa um e vários lugares, para conseguir perpassar as várias disciplinas da educação formal, transborda pelos muros das estruturas físicas escolares, permeia a vida, atingindo todos os estratos das sociedades e os cantos do planeta, transmitindo e buscando ter real significação e valorização, promovendo a difusão dos saberes e transformações significativas em relação aos fatores socioambientais que se estabelecem e alteram as condições de vida, alteram o lugar.

A percepção não é uma ciência do mundo, não é nem mesmo um ato, uma tomada de posição deliberada; ela é fundo sobre o qual todos os atos se destacam e ela é pressuposta por eles. $O$ mundo não é um objeto do qual possuo comigo a lei de constituição; ele é o meio natural e o campo de todos os meus pensamentos e de todas as minhas percepções explícitas. A verdade não "habita" apenas o "homem interior", ou, antes, não existe homem interior, o homem está no mundo, é no mundo que ele se conhece. Quando volto a mim a partir do dogmatismo do senso comum ou do dogmatismo da ciência, encontro não um foco de verdade intrínseca, mas um sujeito consagrado ao mundo (MERLEAU-PONTY, 1999, p. 6).

A percepção de mundo, de lugar, de si mesmo, dos outros, do meio, é função da carga de conhecimentos que a cada dia chega ao ser humano e agrega em sua formação como ser, em suas vivências, os elementos culturais, históricos, os valores e os significados que absorve e que assume como sendo seus, mesmo que transitoriamente, pois assim como os elementos do meio ambiente, os valores, os significados para o ser humano também são diferentes em relação aos lugares e também mutáveis com o tempo. Desta forma,

Compreender o lugar é considerá-lo não como uma soma de objetos, mas como um sistema de relações (subjetivo-objetivo, aparência-essência, mediato-imediato, real e simbólico). [...] 
presenciar os pares dialéticos, o novo e o velho, o tradicional e o moderno, o exógeno e o endógeno, enfim, as mudanças e as permanências (MOREIRA, 2007, p. 49).

Nesta linha, segundo Sá (2005, p. 252), "o padrão cultural é aberto e se transforma, exatamente na práxis dos indivíduos-sujeitos interconectados, na relação de pertencimento entre os ecossistemas e as sociedades humanas". Assim sendo, para perceber os problemas socioambientais que possam existir em determinado lugar, encharcado de significados e sensações históricoculturais, além do conhecimento, o sentido de pertencimento precisa estar potencializado, o que leva ao ato do cuidado, que só é possível aflorar quando se reconhece e se atribui importância, significado efetivo aos fenômenos e aos lugares.

Segundo Sauvé (2005, p. 30), "as mesmas perguntas são formuladas a propósito das realidades e problemáticas educacionais, cuja ligação com as problemáticas ambientais deve ser explícita: a educação é ao mesmo tempo o reflexo da dinâmica social e o cadinho das mudanças." Portanto, a aplicação de questionamentos em todos os meios sociais, como forma de entender suas interrelações e gerar ações sobre os problemas socioambientais também se estende ao meio educacional, a escola, que não é um universo a parte, mas é ou ao menos, deveria ser, o ambiente gerador e catalizador do saber, da reflexão, da crítica social e das transformações, sendo que os questionamentos feitos pela crítica social aos outros setores da sociedade também valem para a área educacional.

\section{Entre o lugar e os sujeitos: onde e com quem as ações se desvelaram}

Após discorrer sobre conceitos e correntes da EA que dialogam com o Projeto, trazendo alguns traços do que é o método fenomenológico, o lugar, a percepção, o pertencimento, o socioambiente e entrelaçar suas relações com a $E A$, cabe trazer agora breve caracterização sobre o lugar onde se desenvolveram as ações e os sujeitos que delas participaram.

O lugar das ações

O Projeto de Ação foi desenvolvido na Escola Municipal de Educação Fundamental Santa Ana, escola pública, que oferta ensino da Pré-escola até o 9o Ano do ensino básico, localizada na Vila Cruzeiro, em Gravataí, em 
funcionamento desde 1978, contando com 448 alunos, em dois turnos, no período da execução do Projeto, de agosto a novembro de 2017.

Por residir e ter toda minha história ${ }^{5}$ de vida neste lugar, na mesma rua onde fica a escola, acompanhando as transformações ocorridas no bairro, entendo ser a escola ponto de convergência de indivíduos da vila e das adjacências, um ponto de referência do lugar. A escola, como um polo de irradiação, absorção e troca de conhecimentos (formais e não formais) é influenciada e influencia o ambiente (social, cultural, econômico...) ao longo do tempo, modifica e é modificada, estando integrada e sendo formada, enquanto comunidade, numa sociedade local e ao mesmo tempo global. Sendo assim, é fonte de indivíduos que podem representar adequadamente o lugar vivido.

Em relação à abrangência geográfica estabelecida no projeto, temos a escola como centro das ações, na Vila Cruzeiro, se estendendo às vilas adjacentes (Central, Cruzeiro II, Parque Olinda, COHAB A...) e outras próximas, onde residem seus alunos. Vilas que compartilham de um mesmo processo histórico de urbanização e ocupação, contando com características socioeconômicas e culturais semelhantes.

A Vila Cruzeiro surge nas décadas de 50 e 60, assim como outras na região metropolitana de Porto Alegre, pelo fracionamento de propriedades até então rurais, distando o município, cerca de $30 \mathrm{~km}$ da capital, integrando a região metropolitana, atraindo migrantes do estado e de fora deste, em busca de melhores oportunidades de vida. Como usual, a partir de grupos que faziam a frente, outros imigrantes os seguiam, estabelecendo fluxos de migração e assim a necessidade de maior e mais rápida expansão urbana nos locais de destino, o que por vezes não atendia as necessidades básicas de infraestrutura e adequada urbanização, o que ainda hoje não ocorre a contento.

Para Brandão (2005, p. 12), "[...] para muita gente chega um dia em que se "muda de lugar". E quando alguém vai embora do lugar onde nasceu e viveu algum tempo, o lugar onde alguém nasceu passa a ser: ali, lá, lá longe, de acordo com o lugar para onde ele foi.".

$\mathrm{Na}$ mudança dos lugares de origem estes migrantes traziam nas bagagens de suas diferentes culturas e lugares, de suas famílias, origens, etnias e vivências sociais. Assim como e com eles, suas características foram se instalando dispersas e mescladas pelas vilas em formação, conforme suas condições socioeconômicas e os diferentes momentos em que vieram, por exemplo, formando vilas com características bem variadas, num mosaico multicultural. Para Heidrich (2016, p. 11), "da memória de formação dessas

\footnotetext{
5 Nesta seção será utilizado o tempo verbal na primeira pessoa do singular por tratar de experiências vividas pelo pesquisador, se tornando assim, vivências pessoais. 
áreas, identifica-se na reunião das diversas experiências de seus moradores que a busca pela casa e por atividades de sustentação da vida se confundem com a própria história das pessoas, como essências do espaço vivido.".

Tais movimentos de migração, ocupação e expansão urbana, são contínuos, modificando constantemente as características, as estruturas dos lugares e suas fisionomias. Desse modo, conforme os diferentes contextos históricos e socioculturais a noção de pertencimento ao lugar e de que o lugar Ihe pertence (de posse), também se modifica, pelas mudanças do próprio indivíduo, pelas mudanças deste de lugar e pelas modificações que ocorrem nos lugares, submetidos a processos dinâmicos no tempo, a constância é a mudança.

Conforme o levantamento de dados com os alunos participantes das ações, obtive a composição dos limites geográficos em 20 ruas, localizadas em 9 vilas da região, onde estes residem, sendo elas: Cruzeiro, Cruzeiro II, Central, COHAB A, Nossa Chácara, Santa Fé, São Luiz, São Vicente e Vila Branca.

Cabe registrar que mesmo os pontos situados além do raio de ação inicialmente pretendido foram considerados, entendendo não haver prejuízos para a pesquisa, considerando a proximidade e as semelhanças socioambientais conforme mapeamento realizado pelos endereços dos alunos e meu conhecimento das realidades dos lugares.

Os sujeitos que participaram

O Projeto de Ação em EA foi apresentado para a Direção, que prontamente apoiou e autorizou sua execução na escola, sendo então apresentado aos professores para a definição de quem acompanharia as ações e quais turmas participariam, bem como o calendário mais adequado para as atividades propostas. Foram definidas as duas turmas do último ano do Ensino Fundamental ( $9^{\circ}$ ano), somando 49 alunos (11\% do total da escola), com o acompanhamento da professora da disciplina de Ciências ${ }^{6}$, que se integrou e apoiou a pesquisa, disponibilizando períodos de aula para as ações, sem com isso acarretar prejuízos aos conteúdos e ao calendário escolar.

Foi de entendimento comum que, em função de estarem no nono ano, estes alunos possuem uma formação mais avançada em termos de conteúdo incluindo os relacionados com temas ambientais e socioambientais, que são abordados nos currículos do sexto e oitavo anos, conforme informou a

\footnotetext{
${ }^{6}$ A Professora da disciplina de Ciências apoiou a execução do Projeto de Ação em EA, por ser vinculado com sua área de formação e atuação, como também por interesse pessoal com os temas ambientais, vendo a oportunidade de trabalha-los com seus alunos por outro enfoque.
}

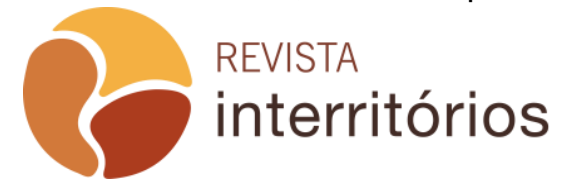

Interritórios | Revista de Educação Universidade Federal de Pernambuco, Caruaru, BRASIL | V.6 N.10 [2020] 
Professora e a Direção. Também, pela faixa etária, entre 14 e 18 anos, entendo, contarem com uma maior vivência e compreensão suficiente para participarem das ações, tendo também condições mais apropriadas de expressar seus conhecimentos e suas posições sobre as questões da pesquisa. Importante ressaltar que a maioria dos alunos participantes, 90\% está na faixa de 14 a 16 anos, que $75 \%$ residem no bairro a mais de 10 anos, sendo que muitos têm suas famílias por mais de uma geração no local, o que permite considerar que conhecem o lugar em que vivem e possuem vivências e experiências diferenciadas estabelecidas ali, com raízes mais profundas.

\section{O trilhar da caminhada: interpretando os fenômenos emergentes}

Para a execução foi elaborado questionário para levantamento de opiniões e percepções dos alunos, contando com cabeçalho para dados de identificação dos respondentes e mais 16 questões sobre aspectos socioambientais, entre objetivas, dissertativas e mistas, permitindo assim, em algumas, que registrassem suas opiniões com suas palavras.

Depois de discutidas as ações do Projeto com a Direção e a Professora, tendo estabelecido as datas para a ação inicial, foi aplicado o questionário nas turmas 91 e 92, na mesma data, em períodos de aula distintos, com o acompanhamento da Professora de Ciências, tendo a participação de todos os alunos presentes, totalizando 37 .

Para a aplicação do questionário não houve preparação das turmas, sendo meu primeiro contato com os alunos. O que ocorreu foram esclarecimentos no momento da apresentação e aplicação, sobre o Projeto, sobre o formulário e a forma de preenchimento, pois a intenção da pesquisa foi buscar a opinião dos alunos dentro dos seus saberes, de seus entendimentos e experiências, construídos nas suas histórias de vida.

Após a aplicação do questionário, propus aos alunos que captassem e encaminhassem imagens sobre aspectos socioambientais que observassem nas ruas onde residem, por onde transitam, no caminho para a escola, tanto positivos, quanto negativos, conforme suas opiniões e percepções do socioambiente. Para tanto, em ambas as turmas os alunos enviariam as imagens pelos grupos de aplicativo WhatsApp $\Theta$, e as repassariam para mim. Tal proposta não se concretizou, pois, conforme os alunos, sendo também de meu conhecimento, há na região a questão da violência, então, por temerem serem alvos de assaltos ao usar os celulares nas ruas, optaram por não as fazerem.

A questão da violência interfere no cotidiano das pessoas, é inegável, afeta o lugar, os ambientes e as atividades escolares, inclusive o desempenho 
tanto dos alunos, quanto dos professores, sendo tema já tratado em muitos estudos. Segundo Abramovay et al (2009, p. 310), "os assaltos, mesmo ocorrendo fora da escola, influem diretamente sobre cotidiano escolar, fomentando um sentimento de insegurança e medo naqueles que vivenciaram este tipo de violência". Ainda, segundo as autoras (2009, p. 311), "diante da recorrência dos casos, alunos desenvolvem estratégias para não serem furtados, como não levar objetos de valor", o que vai ao encontro da alegação dos alunos para não fazerem as imagens.

A não cooperação em relação às imagens pode estar relacionada com a desmotivação dos alunos em participar de atividades nas quais não haja uma contrapartida de seu interesse, uma vez que houve, durante as aplicações dos questionários, manifestações de alunos para a Professora, sobre se haveria alguma "nota" ou recompensa adicional na sua matéria por participarem das ações do Projeto. Conforme a Professora, este seria um comportamento, uma prática comum aos alunos, que interfere no desempenho escolar, infelizmente.

Sobre este aspecto, em relação às motivações externas (extrínsecas), Guimarães (2001, p. 46) coloca que é "a motivação para trabalhar em resposta a algo externo à tarefa ou atividade, como para obtenção de recompensas materiais ou sociais, de reconhecimento, objetivando atender aos comandos ou pressões de outras pessoas ou para demonstrar competências ou habilidades." Também, com relação a este comportamento, temos que,

Muitos professores reclamam da falta de interesse dos alunos nessa idade. Ressaltam que os estudantes não cumprem as tarefas em classe nem em casa, mesmo que valham nota, que relutam para começar uma atividade, que se distraem facilmente, que não respondem às perguntas ou simplesmente dizem: "não sei". [...] Alguns vão para a escola só para ver os amigos. (BZUNECK, 2001).

Independente das causas, como os alunos não encaminharam as imagens, o pesquisador realizou o levantamento fotográfico de aspectos socioambientais com base em seus endereços e nas respostas obtidas nas perguntas do questionário, as quais serão apresentadas a seguir.

\section{Interpretações emergentes das respostas do questionário}

Após a aplicação do questionário, os dados obtidos foram tabulados, organizados, emergindo respostas com as quais foi possível realizar algumas leituras. As perguntas 1 e 2, referentes ao tempo de residência da família e do 
aluno no bairro, possibilitaram saber um pouco sobre a existência de raízes familiares no lugar, do possível maior conhecimento sobre o bairro, do acompanhamento das modificações do lugar, do sentimento de pertencimento que perpassa pelas gerações.

Posteriormente, buscou-se alcançar um dos três objetivos específicos que alicerçaram as ações em EA: verificar as percepções de alunos, em relação às realidades socioambientais que possam estar presentes no lugar em que vivem. Para isto, as questões de 3 a 14, se tornaram guias para que o caminho fosse trilhado, reavivando seus saberes e buscando emergir seus entendimentos sobre os temas da pesquisa.

Iniciando pela questão 3, buscou-se conhecer de quais fontes os alunos tinham informações sobre questões relacionadas ao Meio Ambiente. Isto porque, dependendo das fontes das quais se utilizam os conteúdos e percepções podem ser diferentes, ou ser influenciadas por ideologias sociais e mesmo por correntes de EA, que podem moldar e determinar "verdades". Pelas respostas dos alunos, $83 \%$ apontou a televisão e a internet (sites) empatados como primeira fonte, as Redes Sociais (Facebook ${ }^{\circledR}$, Twitter $\AA$, Whatsapp $\AA$, etc.) com $75 \%$ e em terceiro lugar, escola/professores apareceu com $50 \%$.

Quanto ao uso da internet, de redes sociais e dos mais variados aplicativos, hoje disponíveis nos telefones celulares, estudos abordam tanto os benefícios que este mundo tecnológico representa para a educação, quanto seus malefícios. Nesse sentido, é possível encontrar situações entre a mais tênue e "inocente" distração em detrimento da atenção necessária em sala de aula, da ocupação do tempo de estudos das matérias escolares, por exemplo, passando pelas modificações nos comportamentos e relacionamentos pessoais, familiares e sociais, indo até o surgimento do que já são consideradas patologias, como a dependência destes equipamentos e dos mundos virtuais aos quais estes Ihes dão acesso, o que afeta significativamente os que estão em formação, na fase da adolescência. Assim,

[...] a dependência pela internet ocorre porque o ciberespaço permite experiências que na vida real muitas vezes, seriam frustrantes para o adolescente, como a aceitabilidade pelo grupo, os conhecimentos de interesse, o número de amigos, o acesso rápido a interações como jogos, salas de bate-papo e até mesmo a superexposição nas redes sociais que acentuam o ego dos adolescentes e os fazem sentirem-se mais conectados com os amigos e com o mundo. (GONÇALVES; NUERNBERG, 2012, p. 179).

Na sequência, perguntados sobre quais elementos faziam parte do Meio Ambiente (Questão 4), podendo marcar vários dos itens e mesmo

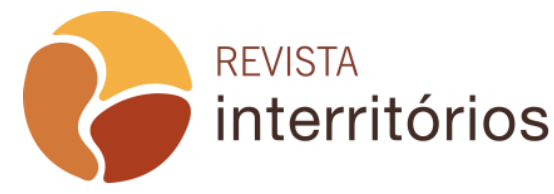

Interritórios | Revista de Educação Universidade Federal de Pernambuco, Caruaru, BRASIL | V.6 N.10 [2020] 
complementar, se obteve o que está no Gráfico 1, abaixo, onde observa-se a relação direta estabelecida com os elementos tidos como naturais (água, rios, lagos, mares, animais, a vegetação, matas e campos, montanhas e planícies, chuvas e ventos), sendo pouco marcados ou mesmo desconsiderados opções com elementos produzidos pelo homem (cidades, ruas, estradas, prédios...). Isto nos remete ao enquadramento dos conceitos da corrente ambiental naturalista, Sauvé (2005).

Cabe destacar que somente 25 alunos consideraram o ser humano como parte do meio ambiente, e apenas 20 , as relações entre os seres vivos, o que sugere falta de entendimento quanto ao conteúdo, quanto aos conceitos sobre o assunto, não quanto ao que foi perguntado. As respostas apareceram reforçadas em outra questão discursiva (Questão 5), onde os alunos escreveram sobre "o que é o Meio Ambiente", predominando elementos tidos como do meio natural.

Na questão 6, perguntados se em sua opinião, a poluição, o desemprego, a pobreza, as desigualdades sociais, a criminalidade, a violência, as deficiências nas áreas de moradia, saúde e educação, são problemas para a população, problemas para a sociedade, problemas sociais, sendo uma questão de resposta direta, obtivemos $35 \mathrm{sim}, 1$ não e um não respondeu, demonstrando terem 0 entendimento das relações dos itens apontados com os problemas que afetam as pessoas, as sociedades, eles próprios.

\section{Gráfico 1 - Que elementos fazem parte do Meio Ambiente}

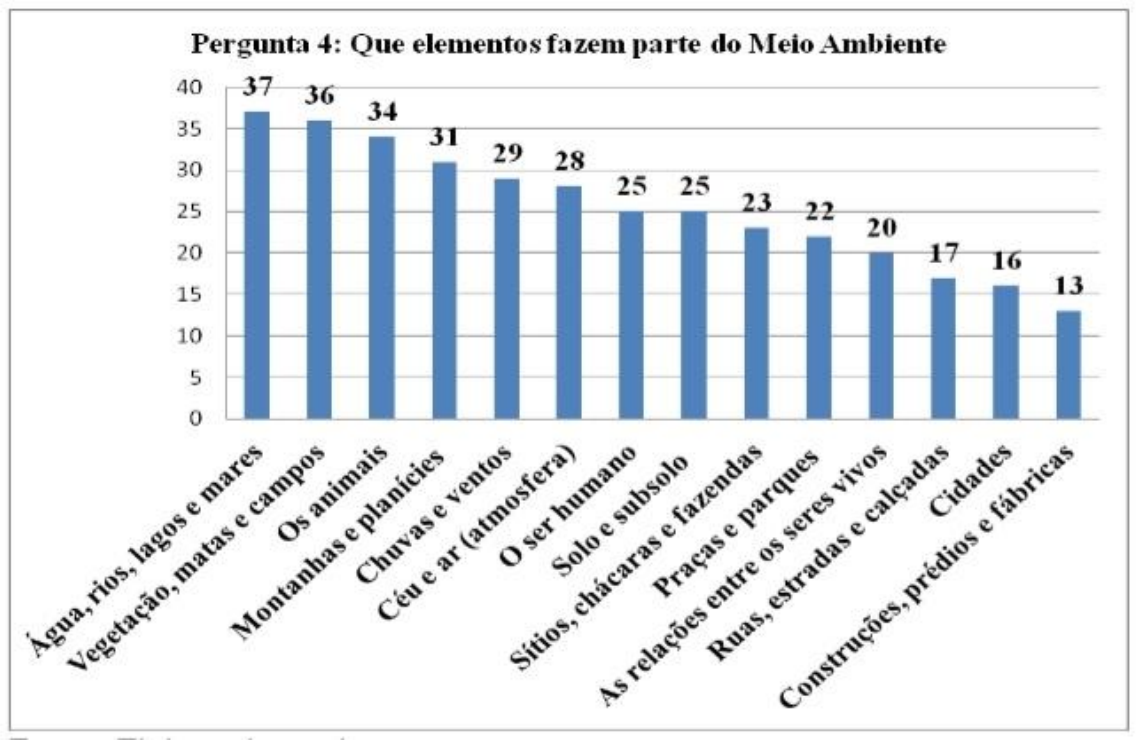

Fonte: Elaborados pelos autores.

Já na questão 7, fazendo a relação entre o social e o ambiental, solicitados se em sua opinião, os problemas ambientais e sociais estão relacionados, estão ligados, podendo ser chamados de socioambientais, obtivemos $36 \mathrm{sim}$ e um

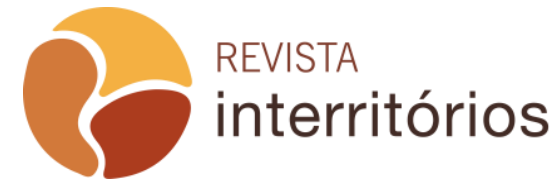

Interritórios | Revista de Educação Universidade Federal de Pernambuco, Caruaru, BRASIL | V.6 N.10 [2020] 
aluno não respondeu. Tal posição leva a crer que os alunos têm pleno entendimento da correlação entre ambiental e social.

$\mathrm{Na}$ questão 8, solicitados se nas suas visões, existem problemas socioambientais, na Rua/Vila onde moram, 32 marcaram que sim, 2, não e um não respondeu, o que leva a crer que já identificaram algum aspecto socioambiental negativo no lugar.

Após este modelo de questionamento que foi agregando conceitos e exemplos, despertando os saberes que os participantes já deveriam ter, a pergunta 9 buscou trazer à tona, na percepção dos alunos, quais problemas socioambientais identificavam na Rua/Vila onde moram, apresentando uma relação de itens, dos quais podiam marcar quantos identificassem, havendo esta orientação por escrito, junto da pergunta, o que também foi salientado por mim na aplicação do questionário, além de haver um espaço para contribuições pessoais. Obtivemos as quantidades de marcações em cada item conforme o Quadro 1.

Quadro 1 - Problemas socioambientais na Rua/Vila, conforme os alunos.

\begin{tabular}{|l|c|}
\hline Problemas socioambientais & Qt. \\
\hline Queima de lixo/galhos pela população & 30 \\
\hline Animais abandonados nas ruas & 30 \\
\hline Lixo/entulhos jogados pelas calçadas e terrenos & 27 \\
\hline Barulho, som alto da vizinhança & 27 \\
\hline Uso de drogas & 27 \\
\hline Barulho, som alto de veículos & 26 \\
\hline Falta de locais para prática de esportes e artes & 26 \\
\hline Violência e criminalidade & 24 \\
\hline Falta de áreas verdes e de lazer (parques e praças) & 23 \\
\hline Pouca arborização nas ruas & 22 \\
\hline Fumaça de carro, ônibus e caminhões & 20 \\
\hline Urbanização deficiente (arruamento, calçadas, esgoto, água...) & 20 \\
\hline Proliferação de insetos, ratos e baratas & 19 \\
\hline Falta de empregos, oportunidades de trabalho & 18 \\
\hline Desigualdades sociais & 18 \\
\hline Fumaça de cigarros em locais comerciais & 17 \\
\hline Inundações & 15 \\
\hline Trânsito complicado pelo no de veículos (mobilidade) & 14 \\
\hline Contaminação do solo & 12 \\
\hline Poluição/lixo nas águas de arroios e do rio & 12 \\
\hline Esgoto a céu aberto & 7 \\
\hline
\end{tabular}




\begin{tabular}{|l|l|} 
Aumento do número de prédios altos & 7 \\
\hline Deficiência de moradias (habitacional) & 7 \\
\hline Aumento da concentração da população na região & 6 \\
\hline
\end{tabular}

Fonte: Elaborado pelos autores.

Buscando na questão 10 o entendimento dos alunos sobre o que poderia ser considerado como pontos ambientais ou socioambientais positivos, o que haveria de bom na Rua/Vila onde moram, foram 32 contribuições. Destacamos que na percepção de $34 \%$ dos alunos surgiu a questão do lixo, de haver 0 cuidado por parte de moradores e o recolhimento pela prefeitura, $25 \%$ destacou a questão da boa arborização das ruas e nos pátios, de haver praças, como importantes espaços de convivência e de não ocorrerem inundações. É relevante perceber que foi citada diversas vezes a relação de cordialidade e colaboração entre as pessoas e a preocupação de moradores em ter atitudes corretas frente ao ambiente em que vivem, com $28 \%$ dos comentários, o que pode estar diretamente relacionado com o sentimento de pertença. Sobre a visão dos alunos de quem é a responsabilidade pelos problemas socioambientais na Rua/Vila onde moram, podendo marcar mais de uma opção e também contribuir escrevendo suas opiniões, na pergunta 11, responderam: os moradores $(91 \%)$, a Prefeitura (73\%), governo Estadual (35\%), governo Federal (32\%), as indústrias e o comércio local, ambas com 19\%, havendo 13 comentários corroborando com as respostas marcadas.

Em relação ao sentimento de pertença dos participantes, as perguntas 12 a 15 foram elaboradas para buscar alcançar o segundo objetivo específico: compreender qual o sentimento dos alunos acerca do lugar em que (com)partilham e vivenciam suas experiências socioculturais. Quanto ao sentimento em relação ao lugar, demonstraram que se sentiam pertencentes ao lugar, pois, sobre se sentiam que faziam parte do lugar, na pergunta 12, obtivemos $73 \%$ Sim e $24 \%$ Não, com comentários de 24 alunos, onde predominou o sentimento de se sentir pertencente, enfocando o lugar, enfatizando as relações com as pessoas, a vizinhança, a vivência no local, mas observando que o lugar está mudando e citando a violência como ponto negativo ao gostar do lugar. Os que disseram não se sentir pertencentes também citaram a questão das transformações do bairro e sua preocupação com a violência, a perda da tranquilidade do lugar na atualidade.

Quando perguntado sobre se sentiam serem também responsáveis por melhorar as condições do lugar onde moram, na pergunta $13,86 \%$ disseram que Sim e $10 \%$, Não, havendo opiniões de 36 alunos, das quais destaco que $97 \%$ tratam diretamente do problema da limpeza do lugar, em especial do lixo, indicando a relevância da percepção deste tema para os respondentes. 
$\mathrm{Na}$ pergunta 14, foi solicitada opinião sobre como as pessoas podem colaborar para melhorar a Rua/Vila onde moram, tendo contribuições de 36 alunos, nas quais, novamente, em diferentes modos de escrever, predominou, na quase totalidade, a questão relacionada com o lixo e a limpeza, aparência das ruas, sendo exemplos: não jogar lixo nas ruas ou nos pátios, recolher e não queimar lixo.

Para ter as opiniões dos alunos sobre suas práticas, o que cada um fazia ou entendia que poderia fazer para reduzir os problemas socioambientais que identificavam na Rua/Vila em que vivem, na pergunta 15, tivemos as contribuições de 33 alunos, destacando que $60 \%$ mencionou a questão sobre os cuidados com o lixo, sua destinação e não poluir as ruas.

Finalmente, na pergunta 16, sobre o que a escola poderia fazer para orientar os alunos e a população no cuidado com o meio ambiente e resolver problemas socioambientais na rua/Vila em que vivem, na opinião de 35 alunos, variadas em termos de redação, mas convergindo todas para a necessidade de dar mais ênfase às informações sobre questões socioambientais e ambientais e na promoção de mais atividades e eventos.

Estas perguntas e as discussões estabelecidas na ação com as imagens possibilitou atingir o terceiro e último objetivo específico: promover discussões que oportunizassem a (re)significação de sentidos socioambientais, sensibilizando para o fortalecimento do pertencimento e do cuidado, abordando de forma mais profunda e crítica tais questões.

\section{O que emergiu a posteriori: olhares para além do visível}

Após a leitura e compreensão acerca das percepções, foi trilhado um dos caminhos propostos no Projeto, pois foi verificado que a percepção dos alunos acerca do socioambiente, das questões socioambientais, do lugar, bem como, o sentido de pertencimento estão entendidos e potencializados, sendo realizadas outras intervenções nas turmas, com a apresentação dos resultados da pesquisa e a promoção de discussões, onde eu e os alunos, com a participação da Professora apoiadora, entrelaçamos diálogos críticos sobre a realidade do bairro e mesmo no contexto mais amplo, município, país, indo ao nível global, das questões socioambientais. Assim, seguindo o pensamento de Cousin (2013, p. 7), "aposto enquanto educadora ambiental em ações com o objetivo de possibilitar a compreensão do lugar, a partir das demandas existentes no contexto local e que sejam capazes de despertar 0 sentimento de pertencimento", buscando aflorar sugestões de possíveis intervenções para dentro e fora do espaço escolar como forma de ação didática propositiva.

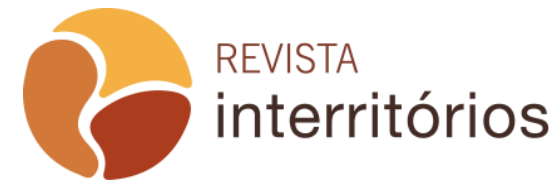

Interritórios | Revista de Educação Universidade Federal de Pernambuco, Caruaru, BRASIL | V.6 N.10 [2020] 
Foram discutidos conceitos (EA, Meio Ambiente, Socioambiente, Pertencimento, Lugar,...), que não foram apresentados antes de ser aplicado o questionário, visto que como mencionado, se buscou as opiniões dos alunos, conforme seus entendimentos, seus conhecimentos prévios, obtidos em suas vivências individuais e sociais. Além disso, foram apresentadas imagens, com uma vista geral aérea da região, com a indicação da escola e de algumas ruas do bairro, fotos de algumas ruas onde residem os alunos, registrando imagens de aspectos socioambientais conforme as respostas do questionário, pelas percepções dos alunos.

Conforme proposto, como ação final, foi realizada divulgação do que emergiu durante a execução do Projeto de Ação, com exposição em painéis no saguão da escola, estes elaborados pelo Pesquisador, em função de não haver disponibilidade de períodos de aula para trabalhar esta atividade com os alunos, como proposto. Foram expostos conceitos envolvidos, resultados em tabelas e gráficos, imagens de aspectos socioambientais positivos e negativos do bairro, além de possíveis soluções apontadas pelos alunos, buscando com isso alcançar a totalidade dos alunos, docentes, funcionários, demais integrantes da comunidade escolar e outras pessoas que transitassem pela escola.

Retomando, para a fenomenologia, toda ocorrência é válida, significativa, deve ser considerada no processo de busca do entendimento sobre a realidade vivida, sobre o pertencimento e as questões socioambientais, objetos deste estudo em EA, sendo referido por Gil (2008, p. 15), que "a pesquisa desenvolvida sob o enfoque fenomenológico procura resgatar os significados atribuídos pelos sujeitos ao objeto que está sendo estudado." Nesse enfoque, não se trata de atingir um ponto final determinado, buscar uma solução, mas relatar e esclarecer sobre os pontos do trajeto percorrido, incluindo as alterações havidas durante 0 percurso, os fenômenos. A busca de explicações e de soluções, por sua vez, são características de outros métodos de pesquisa, não pura, mas aplicada. Ainda, segundo Gil (2008, p. 14), "o intento da fenomenologia é, pois, o de proporcionar uma descrição direta da experiência tal como ela é, sem nenhuma consideração acerca de sua gênese psicológica e das explicações causais que os especialistas podem dar.".

Assim, as atitudes, os comportamentos dos alunos frente às ações propostas para a pesquisa devem fazer parte da própria pesquisa, pois representam fenômeno a ser considerado e relatado, revelando as percepções e o modo como os indivíduos e o grupo percebem e interagem com a realidade do bairro, do seu mundo. A produção de dados, considerando as questões das inter-relações socioambientais entre alunos, escola e comunidade, ocorreu também pela observação dos comportamentos e interações dos alunos nos encontros realizados, na aplicação do questionário, na apresentação e 
discussão sobre os resultados nas turmas e na exposição dos painéis no saguão da escola.

Entendo que os objetivos e a questão norteadora continuaram válidos e foram atingidos, ocorrendo a necessidade de adequações nas ações propostas, correções de rota na execução, o que é também característico da aplicação do método escolhido, fenomenológico, ou seja, a flexibilidade durante o desenvolvimento.

\section{Considerações que orientam ao horizonte}

Embora eu tenha alguma relação com a escola, por alunos, meus familiares, seja conhecido por professores, resida na mesma rua, não sou parte da escola, não sou colega professor, não há uma relação diária, uma vivência na escola, sendo, portanto, alguém externo que foi à escola promover uma ação extracurricular com alguns alunos, em função de minha necessidade para a Especialização que curso. Tal contexto não permitiu maior interação com os alunos, limitando a intervenção ao espaço gentilmente aberto na agenda escolar, o que dificultou o desenvolvimento de ações, mas que não impediu de alcançar os objetivos delineados. Destaco a disposição da Direção e da Professora em acolher e abrir espaço para realizar as ações e assim possibilitar a elaboração deste artigo, bem como, certamente, da fundamental participação dos alunos das turmas 91 e 92 .

Quanto à ação de apresentação e discussão dos resultados da pesquisa e de questões socioambientais, entendo que esta contribuiu para abrir aos alunos um horizonte de reflexão crítica do socioambiente, do lugar e das relações entre os seres humanos e o meio, um despertar para outros olhares. Também foi positiva a exposição no saguão da escola, abrindo as ações, os conteúdos e resultados para a comunidade, buscando informar sobre o que foi desenvolvido na escola e se possível instigar a curiosidade e a busca de saberes sobre os temas abordados.

Embora com alguns percalços e alterações de rota, os resultados foram positivos, lembrando que o interesse nesse projeto era a busca das percepções e das experiências dos alunos, então, não há que se falar em um objetivo, de acerto ou erro, a busca foi pelo sentimento e o entendimento dos alunos. Assim, entendo que as ações do projeto foram realizadas adequadamente e que os resultados revelaram que os alunos participantes demonstraram ter percepções desenvolvidas sobre questões socioambientais, dentro de seus conhecimentos individuais, tanto da educação formal, quanto da não formal, de suas vivências, tendo o sentido de lugar e de pertença ao lugar, em relação ao bairro, aos locais 
onde residem e experienciam suas relações com o ambiente e com o social, cultural e histórico, bastante evidente e desenvolvido.

Mantendo este artigo nos limites dos objetivos do projeto, da questão norteadora, do método eleito e de sua extensão normativa, cabe ressaltar que a pesquisa desenvolvida trouxe uma riqueza de dados que podem abrir a possibilidade para outras leituras, outros trabalhos, investigar as questões abordadas por outros ângulos, com mais profundidade e extensão.

\section{REFERÊNCIAS}

ABRAMOWAY, Miriam; CUNHA, Anna L; CALAF, Priscila P. Revelando tramas, descobrindo segredos: violência e convivência nas escolas. Brasília: Rede de Informação Tecnológica Latino-americana - RITLA, Secretaria de Estado de Educação do Distrito Federal - SEEDF, 2009. 496 p.

BRANDÃO, Carlos R. Aqui é onde eu moro, aqui nós vivemos: escritos para conhecer, pensar e praticar o município educador sustentável. 2.ed. Brasília: MMA, Programa Nacional de Educação Ambiental, 2005. 181 p.

BZUNECK, J. A. A motivação do aluno: aspectos introdutórios. In: BORUCHOVITCH, E.

BZUNECK, J. A. (Org.). A motivação do aluno: contribuições da psicologia contemporânea. Petrópolis: Vozes, 2001. p.09-36.

CARVALHO, Isabel C. M. A invenção do sujeito ecológico: identidade e subjetividade na formação dos educadores ambientais. In: SATO, Michéle; CARVALHO, Isabel C. M. (Orgs.). Educação Ambiental. Porto Alegre: Artmed, 2005, p.53- 66.

COUSIN, Cláudia da S. Pertencer ao navegar, agir e narrar: a formação de educadores ambientais. Rio Grande: Fundação Universidade Federal do Rio Grande, 2010. 207 p.: il.

COUSIN, Cláudia da S. Pertencimento ao lugar e a formação de educadores ambientais: um diálogo necessário. VII EPEA - Encontro Pesquisa em Educação Ambiental. Rio Claro - SP, 07 a 10 de julho de 2013.

Dicionário Priberam da Língua Portuguesa. Holística. Disponível em: $<$ http://www.priberam.pt/dlpo/holística > Acesso em 07/07/2017

GONÇALVES, Bruna G. e NUERNBERG, Denise. A dependência dos adolescentes ao mundo virtual. Revista de Ciências Humanas. Universidade do Extremo Sul Catarinense. Florianópolis. Abril de 2012. Volume 46, Número 1, p. 165-182.

GIL, Antonio C. Métodos e técnicas de pesquisa social. 6ª ed. - São Paulo: Atlas, 2008. 
GUIMARÃES, Mauro. Intervenção Educacional: Do "de grão em grão a galinha enche o papo" ao "tudo junto ao mesmo tempo agora". In: Encontros e Caminhos:

Formação de Educadoras(es) Ambientais e Coletivos Educadores. Júnior, Luiz A. (Org.) Brasília, MMA, Diretoria de Educação Ambiental, 2005, p. 189 - 199.

GUIMARÃES, S. E. R. Motivação intrínseca, extrínseca e o uso de recompensas em sala de

aula. In: BORUCHOVITCH, E.; BZUNECK, J. A. (Org.). A motivação do aluno: contribuições da psicologia contemporânea. Petrópolis: Vozes, 2001. p.58-77.

HEIDRICH, Álvaro L., et al. (Org.). Estruturas e dinâmicas socioespaciais urbanas no Rio Grande do Sul: transformações em tempos de globalização (1991- 2010). Porto Alegre. Editora Letra1, 2016. 336 p.

MERLEAU-PONTY, Maurice. Conversas. 1948. Tradução Fabio Landa; Eva Landa. São Paulo. Martins Fontes, 2004 a. 1a Edição, Coleção Tópicos.

MERLEAU-PONTY, Maurice. Fenomenologia da percepção. 2a Ed. São Paulo: Martins Fontes, 1999, Coleção Tópicos.

MOREIRA, Erika V; HESPANHOL, Rosângela A. de M. O lugar como uma construção social. Revista Formação, n⿳14, volume 2 - p. 48-60. Disponível em:< http://www2.fct.unesp.br/pos/geo/revista/artigos/6 moreira e hespanhol.pdf>. Acesso em 07/06/2017.

SÁ, Lais M. Pertencimento. In: Encontros e Caminhos: Formação de Educadoras(es) Ambientais e Coletivos Educadores. Júnior, Luiz A. (Org.) Brasília, MMA, Diretoria de Educação Ambiental, 2005, p. 247-256.

SADALA, Maria L. A. A fenomenologia como método para investigar a experiência vivida uma perspectiva do pensamento de Husserl e de Merleau-Ponty. FM UNESP /Botucatu. 1995. Disponível em: < http://www.sepq.org.br/lssipeq/anais/pdf/gt1/12.pdf>. Acesso em: 08/06/2017

SAUVÉ, Lucie. Uma cartografia das correntes em Educação Ambiental. In: SATO, Michéle; CARVALHO, Isabel C. M.. (Orgs.). Educação Ambiental. Porto Alegre: Artmed, 2005, p.17- 45.

TASSARA, Eda T. de O. e ARDANS, Omar. Mapeamentos, Diagnósticos e Intervenções Participativos no Campo Socioambiental. in: Mapeamentos, Diagnósticos e Intervenções Participativos no Socioambiente. Série Documentos Técnicos - 15. Órgão Gestor da Política Nacional de Educação Ambiental. Ministério do Meio Ambiente. Brasília, 2007, p. 34-59. 